\title{
Studies of ionospheric F-region response in the Latin American sector during the geomagnetic storm of 21-22 January 2005
}

\author{
Y. Sahai ${ }^{1}$, P. R. Fagundes ${ }^{1}$, R. de Jesus ${ }^{1}$, A. J. de Abreu ${ }^{1}$, G. Crowley ${ }^{2}$, T. Kikuchi ${ }^{3}$, C.-S. Huang ${ }^{4}$, V. G. Pillat ${ }^{1}$, \\ F. L. Guarnieri ${ }^{5}$, J. R. Abalde ${ }^{1}$, and J. A. Bittencourt ${ }^{6}$ \\ ${ }^{1}$ Department of Physics and Astronomy, Universidade do Vale do Paraiba (UNIVAP), São José Dos Campos, SP, Brazil \\ ${ }^{2}$ Atmospheric \& Space Technology Research Associates (ASTRA) LLC, San Antonio, TX, USA \\ ${ }^{3}$ STELAB, Nagoya University, Furo-cho, Chikusa-ku, Nagoya 464-8601, Japan \\ ${ }^{4}$ Institute of Scientific Research, Boston College, Chestnut Hill, MA, USA \\ ${ }^{5}$ Vale Soluções em Energia (VSE), São José dos Campos, SP, Brazil \\ ${ }^{6}$ Instituto Nacional de Pesquisas Espaciais (INPE), São José dos Campos, SP, Brazil
}

Received: 27 September 2010 - Revised: 2 May 2011 - Accepted: 4 May 2011 - Published: 27 May 2011

\begin{abstract}
In the present investigation, we have studied the response of the ionospheric F-region in the Latin American sector during the intense geomagnetic storm of 21-22 January 2005. This geomagnetic storm has been considered "anomalous" (minimum Dst reached $-105 \mathrm{nT}$ at 07:00 UT on 22 January) because the main storm phase occurred during the northward excursion of the $B_{\mathrm{Z}}$ component of interplanetary magnetic fields (IMFs). The monthly mean $F_{10.7}$ solar flux for the month of January 2005 was 99.0 sfu. The Fregion parameters observed by ionosondes at Ramey (RAM; $18.5^{\circ} \mathrm{N}, 67.1^{\circ} \mathrm{W}$ ), Puerto Rico, Jicamarca (JIC; $12.0^{\circ} \mathrm{S}$, $76.8^{\circ} \mathrm{W}$ ), Peru, Manaus (MAN; $2.9^{\circ} \mathrm{S}, 60.0^{\circ} \mathrm{W}$ ), and São José dos Campos (SJC; $23.2^{\circ} \mathrm{S}, 45.9^{\circ} \mathrm{W}$ ), Brazil, during 21-22 January (geomagnetically disturbed) and 25 January (geomagnetically quiet) have been analyzed. Both JIC and MAN, the equatorial stations, show unusually rapid uplifting of the F-region peak heights $(h p \mathrm{~F} 2 / h m \mathrm{~F} 2)$ and a decrease in the $N m \mathrm{~F} 2$ coincident with the time of storm sudden commencement (SSC). The observed variations in the F-region ionospheric parameters are compared with the TIMEGCM model run for 21-22 January and the model results show both similarities and differences from the observed results. Average GPS-TEC (21, 22 and 25 January) and phase fluctuations (21, 22, 25, 26 January) observed at Belem (BELE; $1.5^{\circ} \mathrm{S}, 48.5^{\circ} \mathrm{W}$ ), Brasilia (BRAZ; $15.9^{\circ} \mathrm{S}, 47.9^{\circ} \mathrm{W}$ ), Presidente Prudente (UEPP; $22.3^{\circ} \mathrm{S}, 51.4^{\circ} \mathrm{W}$ ), and Porto Alegre (POAL; $30.1^{\circ} \mathrm{S}, 51.1^{\circ} \mathrm{W}$ ), Brazil, are also presented. These
\end{abstract}

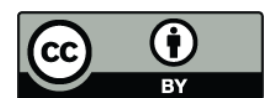

Correspondence to: Y. Sahai (sahai@ univap.br)
GPS stations belong to the RBMC/IBGE network of Brazil. A few hours after the onset of the storm, large enhancements in the VTEC and NmF2 between about 20:00 and 24:00 UT on 21 January were observed at all the stations. However, the increase in VTEC was greatest at the near equatorial station (BELE) and enhancements in VTEC decreased with latitude. It should be pointed out that no phase fluctuations or spread-F were observed in the Latin American sector during the postsunset pre-reversal time in the geomagnetic disturbance (21 January). The disturbance dynamo electric field possibly resulted in downward drift of the F-region plasma and inhibited the formation of spread-F.

Keywords. Ionosphere (Ionosphere-magnetosphere interactions)

\section{Introduction}

Ionospheric storms are closely associated with geomagnetic storms and are an extreme example of space weather events. The response of the ionosphere to storms is rather complicated. As mentioned by Schunk and Sojka (1996) weather disturbances in the ionosphere-thermosphere system can have a detrimental effect on both ground-based and space-based systems. Several investigators (e.g. Orus et al., 2007; Sreeja et al., 2009; Kane, 2009; Matthiä et al., 2009; McKenna-Lawlor et al., 2010) have studied different aspects associated with the geomagnetic storm or geomagnetic disturbed period around the third week of January 2005. Du et al. (2008) have investigated the storm on 21-22 January 2005

Published by Copernicus Publications on behalf of the European Geosciences Union. 
and called it an "anomalous" geomagnetic storm as the storm main phase occurs during northward interplanetary magnetic fields (IMFs). As described by Lee et al. (2010), a southward IMF condition is generally considered to be the most fundamental precondition for a storm or substorm to occur. The Dst index typically starts to decrease about an hour after the IMF turns southward. After the IMF has turned northward, the storm starts to recover. Delays normally have never been longer than one or at most two hours when the Dst index starts to decrease. Lee et al. (2010) in their recent paper entitled "Can intense substorms occur under northward IMF conditions" mention that the occurrence of such (intense) substorms implies that a certain (large) amount of energy remains in the tail even under northward IMF conditions. Crowley et al. (2010) also showed that large amounts of energy can be deposited into the high latitude regions during $B_{\mathrm{z}}$ northward or strong $B_{\mathrm{y}}$ conditions, driving large perturbations in the neutral density at times when they would not previously have been expected. However, they argue that the energy is deposited as a result of reconnection in the lobes under $B_{\mathrm{Z}}$ northward or strong $B_{\mathrm{y}}$ conditions, and not stored in the tail.

As mentioned by Schunk and Sojka (1996), geomagnetic storms occur when there is a large sudden increase in the solar wind speed. A typical geomagnetic storm generally has three phases; initial, main and recovery. Frequently, storms begin abruptly with sudden storm commencement (SSC), but storms can also begin gradually without an SSC. During the main or growth phase, the magnetospheric electric field and particle precipitation patterns expand, the electric fields become stronger, and precipitation becomes more intense with increased Joule and particle heating, and electrojet currents. Schunk and Sojka (1996) further point out that the energy input to the upper atmosphere maximizes during the main or growth phase, while during the recovery phase the geomagnetic activity and energy input decrease. As described by Abdu (1997; see also Buonsanto, 1999) major modifications in the equatorial ionosphere-thermosphere system during magnetospheric disturbances are produced by (a) prompt equatorward penetration of magnetospheric/high latitude electric fields (see also Senior and Blanc, 1984; Spiro et al., 1988), and (b) disturbance dynamo driven by enhanced global thermospheric circulation resulting from energy input at high latitude (see also Blanc and Richmond, 1980). Recently, Kikuchi et al. (2008) and Veenadhari et al. (2010) have investigated penetration of magnetospheric electric fields to the equator during magnetic disturbances.

In this paper, ionospheric observations (ionospheric sounding and GPS) obtained in the Latin American sector at several stations during the geomagnetic storm on 21-22 January 2005 are presented. The principal objectives of the present investigation have been to study the presence or absence of equatorial spread-F (ESF) and dynamics of the Fregion in the Latin American sector during this anomalous geomagnetic storm. A comparison of the ionospheric sound- ing observations with the TIME-GCM results is also presented. The ionospheric sounding observations obtained on $21\left(\sum \mathrm{Kp}=35-\right)$ and $22\left(\sum \mathrm{Kp}=32\right)$ January at different stations during a geomagnetic disturbed period are compared with quiet time observations on $25\left(\sum \mathrm{Kp}=8-\right)$ January.

\section{Observations}

McKenna-Lawlor et al. (2010) described a large solar flare on 20 January 2005 that was accompanied by a coronal mass ejection (CME) which arrived at the magnetopause at about 17:12 UT, 21 January, and produced a strong pressure pulse. Following the CME, an intense geomagnetic storm occurred on 21-22 January 2005, with sudden storm commencement (SSC) at 17:12 UT on 21 January. A minimum Dst of $-105 \mathrm{nT}$ was attained at 07:00 UT on 22 January. In this paper we present and discuss simultaneous ionospheric sounding observations obtained by the UNIVAP network (using Canadian Advanced Digital Ionosondes (CADIs), (Grant et al., 1995) on UT days 21, 22 January (geomagnetically disturbed), and 25 January (geomagnetically quiet) at São José dos Campos (hereafter referred as $\mathrm{SJC} ; 23.2^{\circ} \mathrm{S}, 45.9^{\circ} \mathrm{W}$; dip latitude $18.1^{\circ} \mathrm{S}$ ) and Manaus (hereafter referred as MAN; $2.9^{\circ} \mathrm{S}, 60.0^{\circ} \mathrm{W}$; dip latitude $5.8^{\circ} \mathrm{N}$ ), Brazil. We also present data from digisonde stations at Ramey (hereafter referred as RAM; $18.5^{\circ} \mathrm{N}, 67.1^{\circ} \mathrm{W}$; dip latitude $27.5^{\circ} \mathrm{N}$ ), Puerto Rico, and Jicamarca (hereafter referred as JIC; $12.0^{\circ} \mathrm{S}, 76.8^{\circ} \mathrm{W}$; dip latitude $0.4^{\circ} \mathrm{N}$ ), Peru. The different ionospheric parameters reported here from SJC and MAN (every $15 \mathrm{~min}$ ) were obtained using the computer program developed at UNIVAP as "UNIVAP Digital Ionosonde Data Analysis - UDIDA", and those from RAM and JIC (every $15 \mathrm{~min}$ ) were obtained from the website http://ulcar.uml.edu/DIDB/DIDBHome.html. The GPS-TEC and phase fluctuations (rate of change of TEC, TEC $\mathrm{min}^{-1}$ ) data on 21, 22 and 25 January are presented from 4 stations: Belem (hereafter referred as BELE; $1.5^{\circ} \mathrm{S}, 48.5^{\circ} \mathrm{W}$; dip latitude $1.7^{\circ} \mathrm{N}$ ), Brasilia (hereafter referred as BRAZ; $15.9^{\circ} \mathrm{S}$, $47.9^{\circ} \mathrm{W}$; dip latitude $11.1^{\circ} \mathrm{S}$ ), Presidente Prudente (hereafter referred as UEPP; $22.3^{\circ} \mathrm{S}, 51.4^{\circ} \mathrm{W}$; dip latitude $14.6^{\circ} \mathrm{S}$ ), and Porto Alegre (hereafter referred as POAL; $30.1^{\circ} \mathrm{S}, 51.1^{\circ} \mathrm{W}$; dip latitude $20.5^{\circ} \mathrm{S}$ ), Brazil. All the GPS stations belong to the "Rede Brasileira de Monitoramento Continuo (RBMC)" operated by the "Instituto Brasileiro de Geografia e Estatistica (IBGE)".

All the Brazilian monitoring stations (SJC, BELE, BRAZ, UEPP and POAL) have UT $=\mathrm{LT}+3 \mathrm{~h}$, except MAN which has $\mathrm{UT}=\mathrm{LT}+4 \mathrm{~h}$. RAM and JIC have $\mathrm{UT}=\mathrm{LT}+5 \mathrm{~h}$. Dip latitudes for different stations were calculated using IGRF10 (2005) at an altitude of $300 \mathrm{~km}$. Figure 1 shows a map of the locations of the digital ionosonde and GPS receiver stations in Brazil. It should be mentioned that Manaus and Belem are equatorial stations and will see the equatorial uplifting more clearly. Whereas other stations are located 


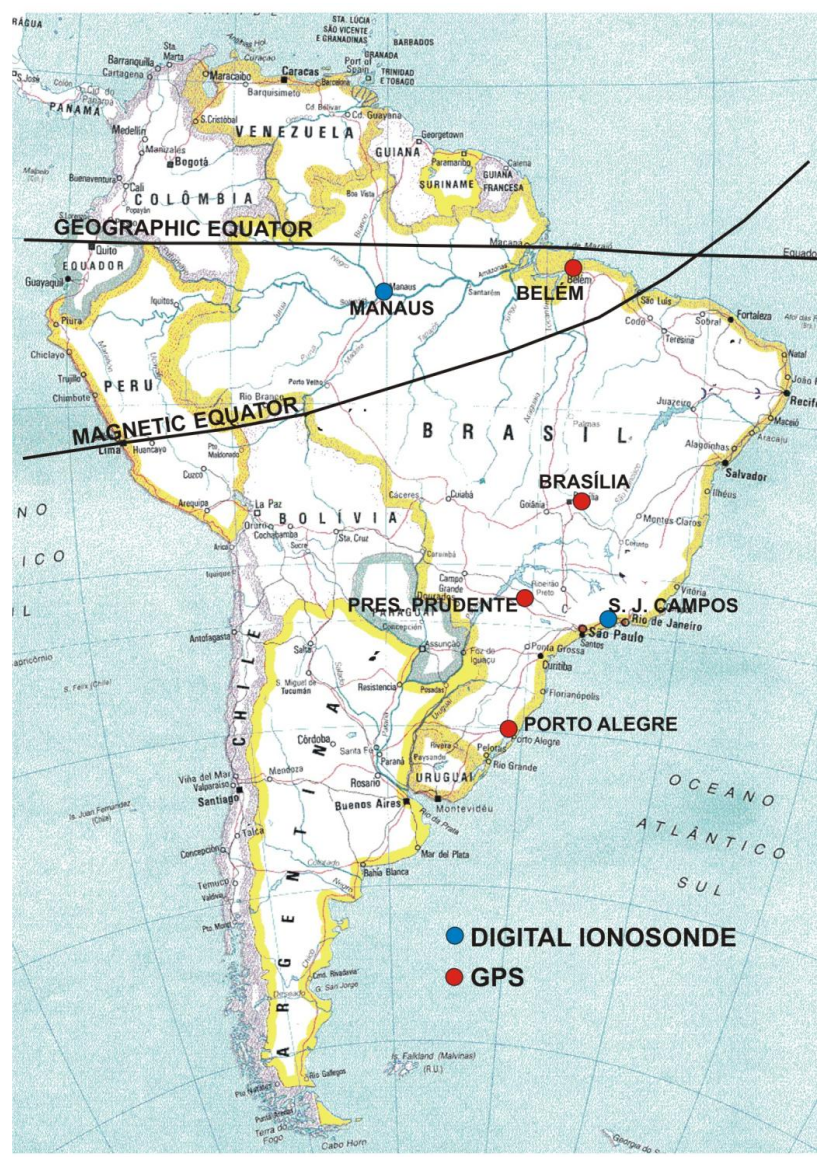

Fig. 1. A map of South America showing the locations of the digital ionosonde and GPS stations in Brazil, used in the present investigations. Also, geographic and dip equators are shown.

in low latitude region and typically see the fountain effect more clearly. However, the exact latitude of the dominant downward flow cannot be easily determined. The dominance occurs when the vertical (downward) component of the field-aligned plasma flow is greater than the vertical (upward) component of the $\boldsymbol{E} \times \boldsymbol{B}$ drift. Also, the observed ionospheric parameters during the storm at different stations are compared with from the TIME-GCM (ThermosphereIonosphere-Mesosphere-Electrodynamics General Circulation Model) (Roble and Ridley, 1994; Crowley et al., 1999, 2010) simulation results.

Figure 2 shows the variations of the geomagnetic indices (Kp, AE, and Dst), solar wind (number density and velocity), interplanetary magnetic field (IMF - three magnetic field components $B_{\mathrm{x}}, B_{\mathrm{y}}$, and $B_{\mathrm{z}}$ ), and total magnetic field $(\boldsymbol{B})$, observed on UT days 21 and 22 January. The solar wind and IMF data were obtained from the ACE satellite website http://www.srl.caltech.edu/ACE/. It should be mentioned that the maximum in $d \mathrm{Dst} / d t$ (rate change of Dst) was between 20:00 and 21:00 UT and the peak AE of about 3000 nT occurred at 17:45 UT. A maximum value of AE could be caused by a substorm expansion phase or by solar wind pressure impulse.

Various solar wind and ground-based magnetometer results are shown in Fig. 3 for 21 January 2005. Du et al. (2008) mention a possible explanation (for the anomalous geomagnetic storm of 21-22 January 2005) that there is first energy storage in the magnetotail and then a delayed energy injection into the inner magnetosphere. In other words their interpretation is that the energy input was associated with the southward IMF field evident in Fig. 3 (second panel from top). However, it appears that this event is very unusual because the solar wind pressure reaches to about $100 \mathrm{nPa}$ (top panel of Fig. 3). The solar wind energy is transferred to the magnetotail during the period of southward IMF between 18:00 and 19:00 UT. The magnetotail is greatly compressed by the extreme solar wind pressure after 18:45 UT, and the energy previously stored in the magnetotail is then released and causes the enhancement of the ring current and the storm main phase. The bottom panel in Fig. 3 shows the difference between the northward magnetic fields at JIC (dip latitude $0.4^{\circ} \mathrm{N}$ ) and Piura (dip latitude $6.8^{\circ} \mathrm{N}$ ), Peru, which is also termed the equatorial electrojet (Anderson et al., 2002). It is observed in Fig. 3, positive electrojet occurs between about 17:25 and 20:00 UT, corresponding to an eastward electric field in this interval. The eastward electrojet/electric field lasts until about 20:00 UT, covering most of the storm main phase. In addition as described by Huang et al. (2008), solar wind pressure enhancements, without geomagnetic storms, can cause an eastward penetration electric field in the dayside equatorial ionosphere (see $h p \mathrm{~F} 2 / h m \mathrm{~F} 2$ at JIC and MAN in Fig. 4).

\section{Thermosphere-Ionosphere-Mesosphere- Electrodynamics Genaral Circulation Model (TIME- GCM)}

The Thermosphere Ionosphere Mesosphere Electrodynamics General Circulation Model (TIME-GCM) developed by Roble and Ridley (1994) predicts winds, temperatures, major and minor species concentrations, electron densities and electrodynamic quantities globally from $30 \mathrm{~km}$ to about $600 \mathrm{~km}$ altitude. The standard TIME-GCM uses a fixed geographic grid with a $5^{\circ} \times 5^{\circ}$ horizontal resolution, and a vertical resolution of a half pressure scale height. The model time-step is typically $2-3 \mathrm{~min}$, but rapid changes and storms usually require $1 \mathrm{~min}$ time-steps to maintain model stability. The TIME-GCM has played an important role in understanding the characteristics of the upper atmosphere. An essential part of the TIME-GCM's success is due to its detailed input specification. Among the inputs is the solar ultraviolet flux at $57 \mathrm{key}$ wavelengths, parameterized by the solar $10.7 \mathrm{~cm}$ radio flux $\left(F_{10.7}\right)$, as discussed by Roble (1995), and seasonal climatology for tidal inputs at the lower boundary. Properties of the semidiurnal tides propagating up from the 
21 JAN 2005

22 JAN 2005

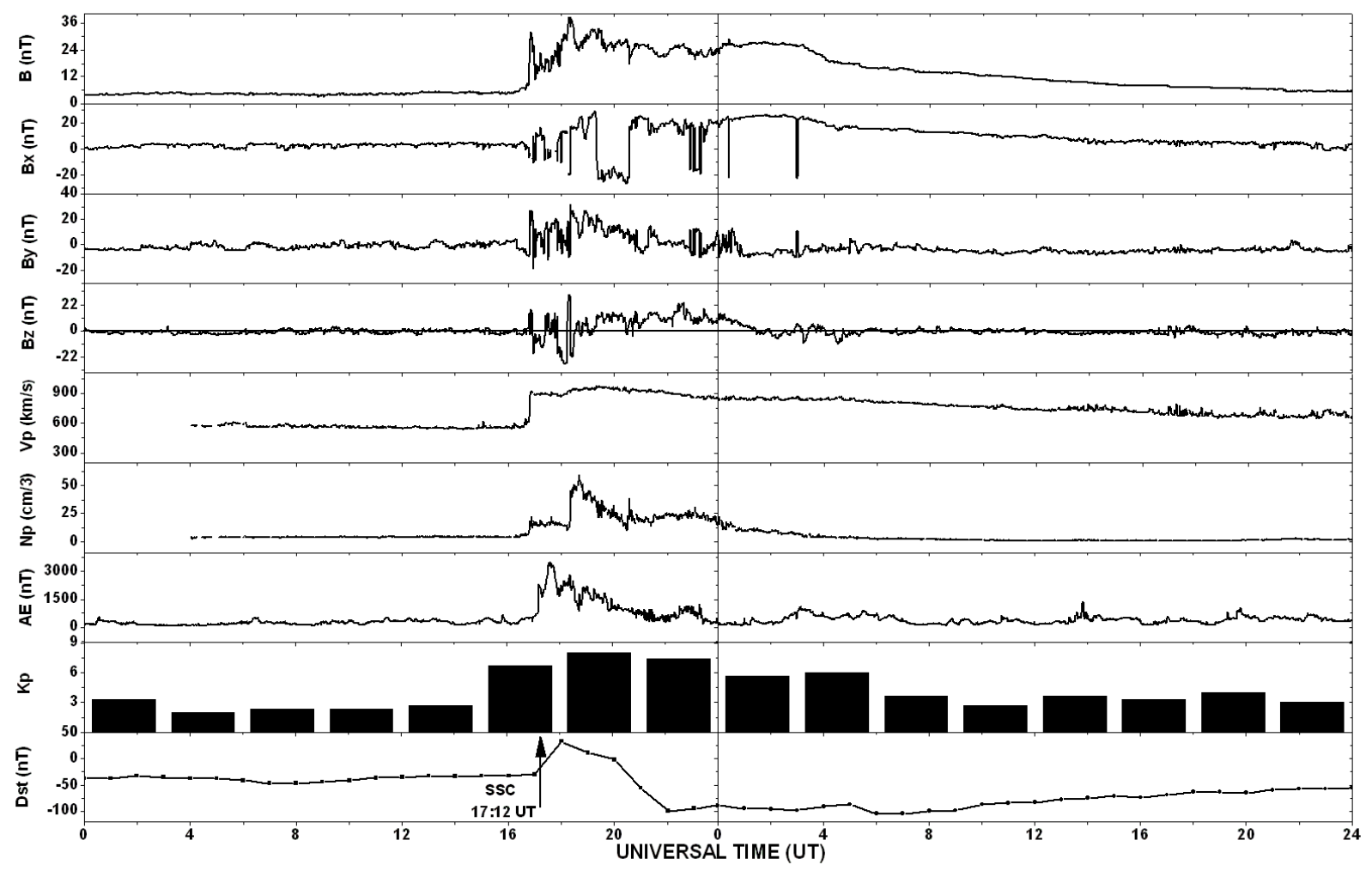

Fig. 2. Variations of geomagnetic indices (Kp, AE, and Dst), solar wind (number density and velocity), and interplanetary magnetic field (IMF) (total $(\boldsymbol{B})$ and three components viz., $B_{\mathrm{X}}, B_{\mathrm{y}}$, and $B_{\mathrm{Z}}$ ) observed on 21 and 22 January 2005. The solar wind and IMF data were obtained from the ACE satellite site http://www.srl.caltech.edu/ACE/.

lower atmosphere are generally unknown for specific simulation intervals, and are specified at the lower boundary of the TIME-GCM (e.g. Fesen et al., 1986) using seasonal averages derived from the Global Scale Wave Model of Hagan et al. (1999), although they can be tuned for specific dates if sufficient tidal data are available.

Other inputs required by the TIME-GCM include high latitude particle precipitation and electric fields in order to correctly specify the Joule heating and momentum forcing. Roble and Ridley (1987) developed an analytical formulation of the auroral oval, and introduced the use of the analytical Heelis convection model (Heelis et al., 1982), including distortions attributable to the interplanetary magnetic field (IMF) $B_{\mathrm{y}}$ component. Instead of these simple climatological electrodynamics inputs, the TIME-GCM can be driven using high latitude inputs from the Assimilative Mapping of Ionospheric Electrodynamics (AMIE) algorithm developed by Richmond and Kamide (1988) and Richmond (1992). This approach was pioneered by Crowley et al. (1989), and subsequent papers.

Obviously, the quality of the model inputs determines the quality of the outputs. For this study, the TIME-GCM was driven by high latitude electrodynamic fields from the AMIE algorithm. The AMIE algorithm is run routinely at ASTRA, ingesting data from ground-based magnetometers, $\mathrm{Su}-$ perDARN radars and DMSP satellites. Due to the assimilative nature of the AMIE technique, AMIE provides the most accurate distributions of the high latitude electrodynamics available to the community. The AMIE potential pattern is provided on a 1.5 degree latitude grid with a $5 \mathrm{~min}$ cadence. The AMIE inputs to the TIME-GCM are then also updated on a 5-min cadence so that the TIME-GCM can reproduce with high fidelity the variability of the storm-time energy inputs to the atmosphere. There is a significant improvement in the fidelity with which the TIME-GCM reproduces the behavior of the global thermosphere and ionosphere when AMIE is used, rather than climatological high latitude inputs. The AMIE fields include the electric field distribution, and particle precipitation. The improved fidelity in the TIME-GCM storm simulations that arises from using the high cadence AMIE drivers has been demonstrated in various simulations, such as the November 2003 storm (Crowley and Meier, 2008). The particle precipitation specified in the TIME-GCM produces changes in the high latitude conductivity distribution. At the same time, the high latitude E-fields then produce enhanced Joule heating and momentum forcing 


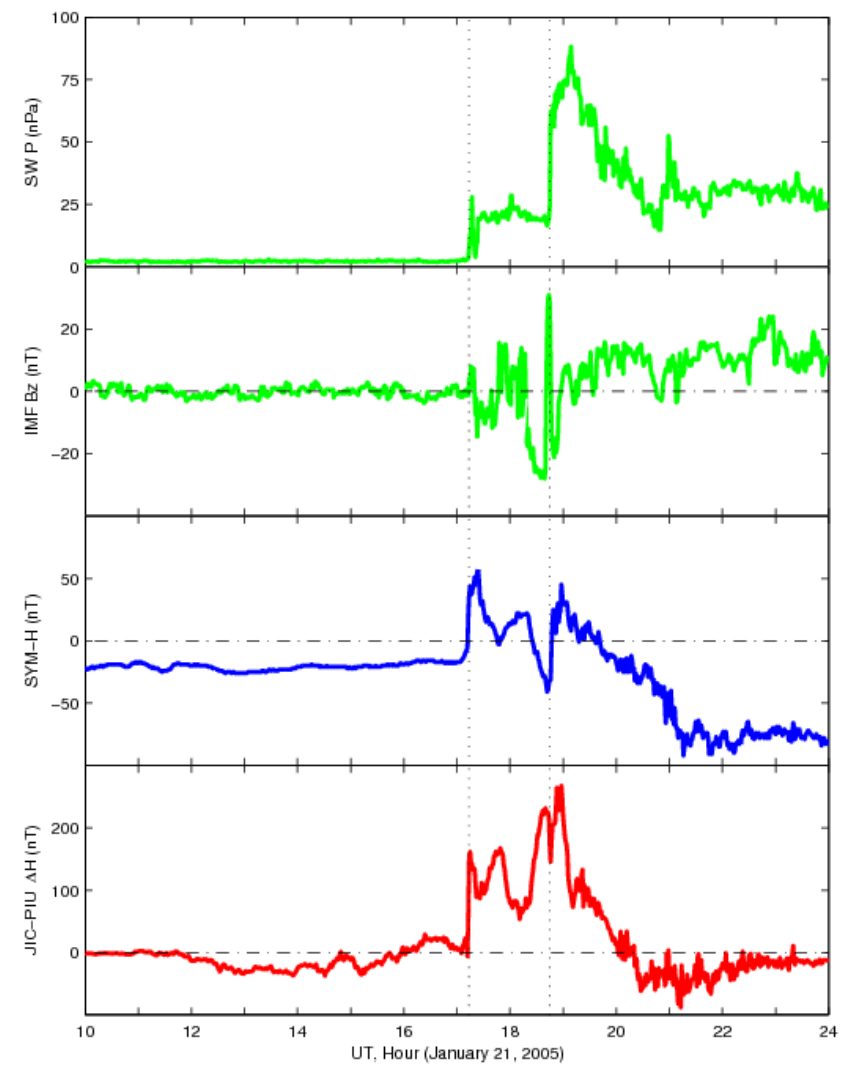

Fig. 3. Time variations of solar wind pressure (nPa), IMF $B_{\mathrm{Z}}(\mathrm{nT})$, sym-H (nT), and difference between northward magnetic fields at Jicamarca and Piura, Peru, during the period 10:00 to 24:00 UT on 21 January 2005.

in the model that also vary with a 5 min cadence, producing a realistic storm-time response in the model. To be clear, there is no single potential pattern driving the TIME-GCM; since the AMIE fields are driven by actual data from groundbased magnetometers, SuperDARN radars and DMSP satellites, the potential patterns are highly variable.

For the current storm study, the high latitude energy inputs to the model are illustrated by Fig. 4a and b, which show the time series of the Hemispheric Power, and the hemispheric integrated Joule heating for the Northern Hemisphere from AMIE, respectively. The hemispheric power provides a measure of the energy inputs from the particles in the aurora. The peak energy inputs to the storm occurred around 20:00 UT, when the Hemispheric Power input reached values near $500 \mathrm{GW}$, and the Joule heating was about $1200 \mathrm{GW}$ in the Northern Hemisphere.

\section{Results and discussion}

Figures 5 and 6 show, respectively, the time variations of the observed peak electron density $\left(\mathrm{Nm} F 2 \mathrm{~m}^{-3}\right)$ (red lines) and peak height $(h p \mathrm{~F} 2=$ virtual height at $0.834 f o \mathrm{~F} 2)$ (red lines)

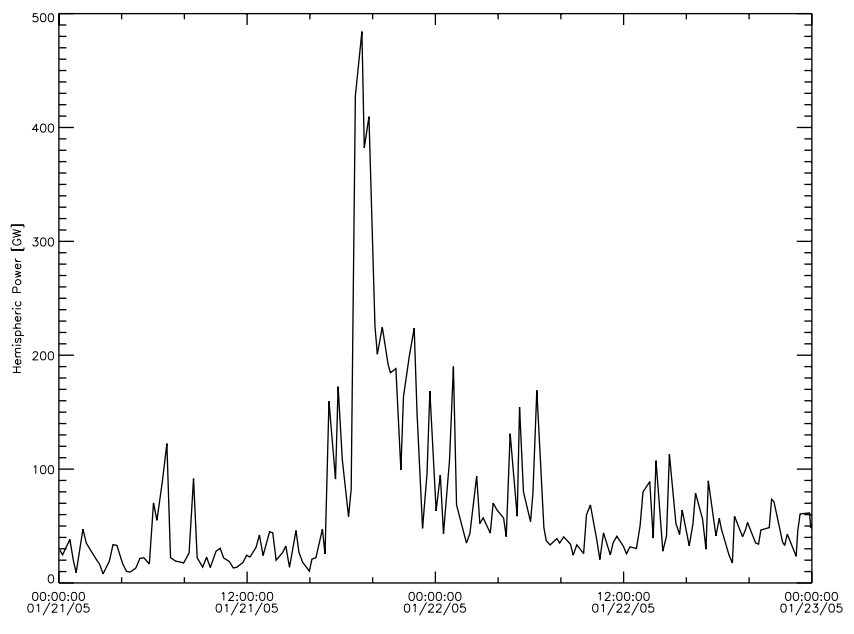

Fig. 4a. The time series of the Hemispheric Power from AMIE.

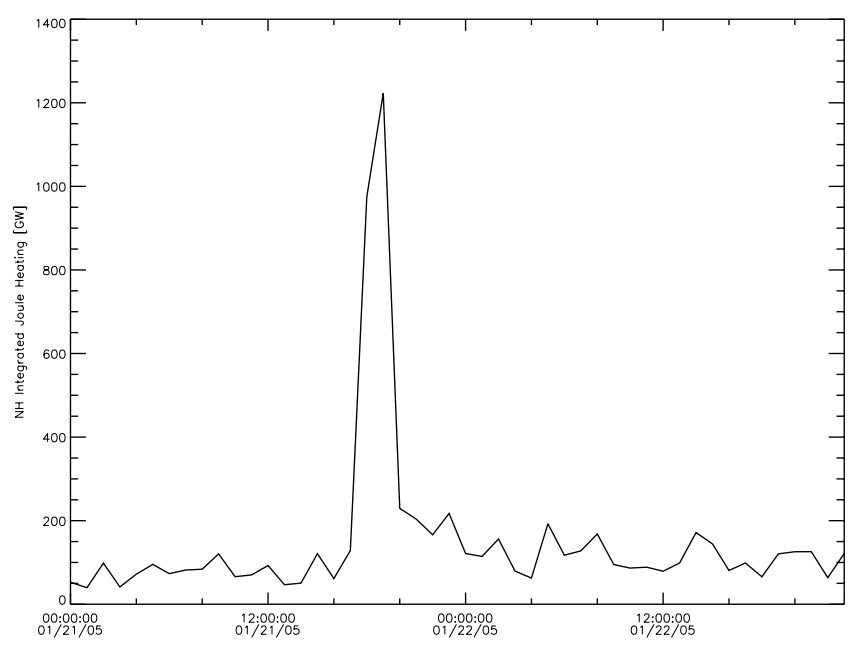

Fig. 4b. The time series of the hemispheric integrated Joule heating for the Northern Hemisphere from AMIE.

of the ionospheric F-region at RAM, JIC, MAN, and SJC on UT days 21 and 22 January (geomagnetically disturbed). The corresponding quiet ionospheric parameters (green lines) observed at different ionospheric sounding stations on 25 January (green lines) are also shown in Figs. 5 and 6, together with ionospheric parameters ( $N m \mathrm{~F} 2$ and $h m \mathrm{~F} 2)$ calculated by the TIME-GCM (black lines). In the present investigation the observed $h p F 2$ values at the Brazilian ionospheric sounding stations MAN and SJC (it is much easier to get these values from the ionograms through the computer program UDIDA) have been compared with $h m \mathrm{~F} 2$ calculated by the TIME-GCM. It should be mentioned that Batista et al. (1991) have shown that the parameter $h p \mathrm{~F} 2$ (obtained directly from ionograms) could differ from the parameter $h m \mathrm{~F} 2$ (obtained through height inversion of ionograms) by $\leq 50 \mathrm{~km}$ during daytime and by $\leq 10 \mathrm{~km}$ during nighttime. Since the peak 


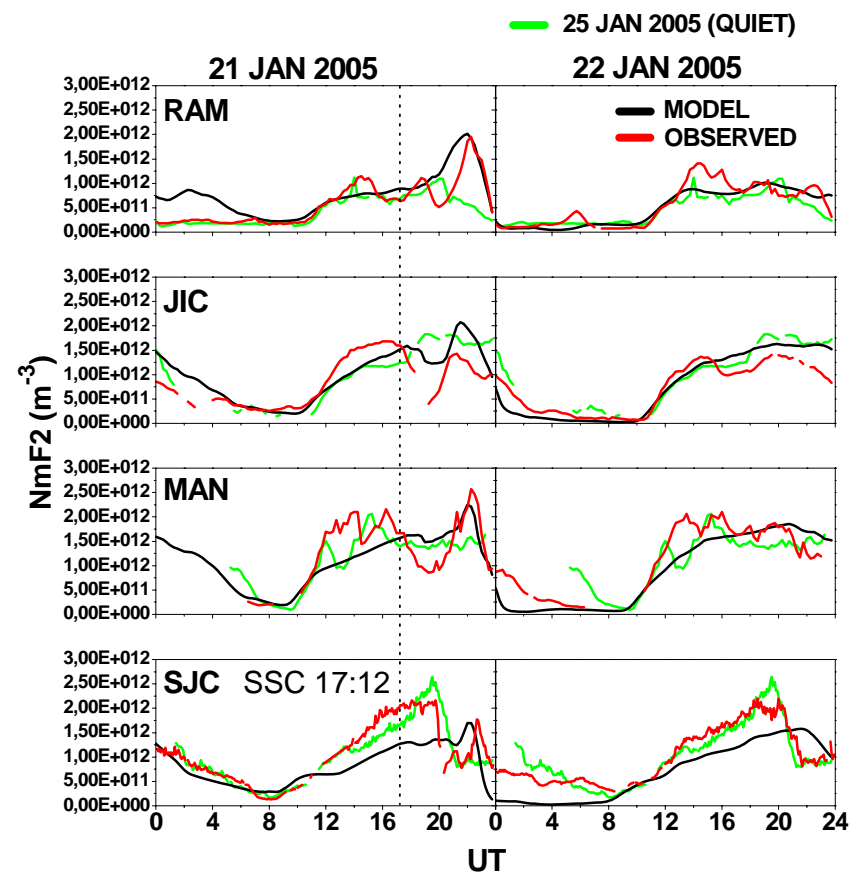

Fig. 5. Time variations of peak electron density of the ionospheric F-region $(\mathrm{NmF})\left(\mathrm{m}^{-3}\right)$ observed on 21 and 22 January 2005 at Ramey (dip lat. $22.7^{\circ} \mathrm{N}$ ), Jicamarca (dip lat. $0.4^{\circ} \mathrm{N}$ ), Manaus (dip lat. $5.8^{\circ} \mathrm{N}$ ), and S. J. Campos (dip lat. $18.1^{\circ} \mathrm{S}$ ) (red lines) along with the TIME-GCM results (black lines). Also, NmF2 observations at the four stations on a quiet day (25 January 2005) (green lines) are shown. The hatched vertical line on 21 January indicates the time (17:12 UT) of storm sudden commencement (SSC).

height changes are fairly large during the storm, it appears that the use of the ionospheric parameter $h p \mathrm{~F} 2$ even during the daytime is probably reasonable.

The TIME-GCM was run with appropriate forcing for the geomagnetic disturbance and solar flux on UT days 21 and 22 January. Specifically, the high latitude particle and convection forcing is specified by the Assimilative Mapping of Ionospheric Electrodynamics (AMIE) technique. AMIE assimilates magnetometer, DMSP and SuperDARN data to produce the electrodynamic specification (see Crowley et al., 2010) used by the TIME-GCM. AMIE is run at a $5 \mathrm{~min}$ cadence, and so the TIME-GCM is able to capture much of the variability in the forcing.

A perusal of Fig. 5 indicates that the observed $N m \mathrm{~F} 2$ at different ionospheric sounding stations after the SSC on 21 January and $N m \mathrm{~F} 2$ simulated by the TIME-GCM are often fairly similar (although there are some differences). Significant differences exist between the TIME-GCM simulations and observations in $N m \mathrm{~F} 2$ at equatorial stations (JIC and MAN) during 17:20 and 20:00 UT on 21 January. The model appears not to have captured the remarkable observed $N m \mathrm{~F} 2$ decreases during this period, and the model does not reproduce the $200 \mathrm{~km}$ increase of $h m \mathrm{~F} 2$ at both stations.

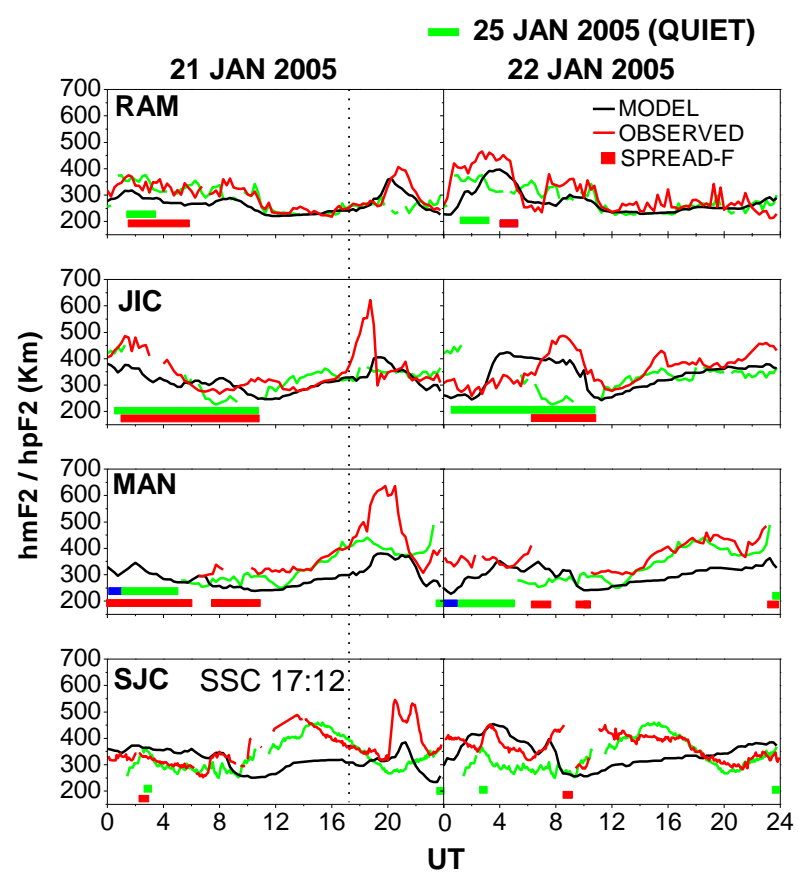

Fig. 6. Time variations of peak height of the ionospheric Fregion $(h p \mathrm{~F} 2=$ virtual height at $0.834 f o \mathrm{~F} 2)(\mathrm{km})$ observed on 21 and 22 January 2005 at Manaus (dip lat. $5.8^{\circ} \mathrm{N}$ ) and S. J. Campos (dip lat. $18.1^{\circ} \mathrm{S}$ ) (red lines). In addition, time variations of peak height of the ionospheric F-region $h m \mathrm{~F} 2(\mathrm{~km})$ observed on 21 and 22 January 2005 at Ramey (dip lat. $22.7^{\circ} \mathrm{N}$ ) and Jicamarca (dip lat. $0.4^{\circ} \mathrm{N}$ ) are shown (red lines). The TIME-GCM $h m \mathrm{~F} 2$ results for different stations are shown (black lines). Also, $h p \mathrm{~F} 2 / h m \mathrm{~F} 2$ observations at the four stations on a quiet day (25 January 2005) (green lines) are shown. The hatched vertical line on 21 January indicates the time (17:12 UT) of storm sudden commencement (SSC).

The arrival of the penetration electric field can be identified from the equatorial electrojet. As presented in the bottom panel of Fig. 3, the electrojet shows a sudden increase at 17:23 UT. An enhancement of the eastward electrojet corresponds to an increase of an eastward electric field. The remarkable correlation between the solar wind change and the enhancement of the electrojet clearly indicates the arrival of the penetration electric field at the equatorial ionosphere.

The effect of the penetration electric field can be identified most easily from the equatorial stations. The electric field causes an enhanced fountain process and results in the decrease of the electron density and TEC over the magnetic equator, such as the stations at JIC and MAN. In contrast, SJC (dip latitude $18.1^{\circ} \mathrm{S}$ ) and RAM (dip latitude $27.5^{\circ} \mathrm{N}$ ) are located at higher low and middle latitudes. An eastward penetration electric field will cause an upward ExB drift in the equatorial region (MAN and JIC), and the plasma particles then flow down along geomagnetic field lines. In general, the change of the F-region electron density or TEC at middle latitudes caused by penetration electric fields is weaker than that at the magnetic equator. Penetration electric fields 


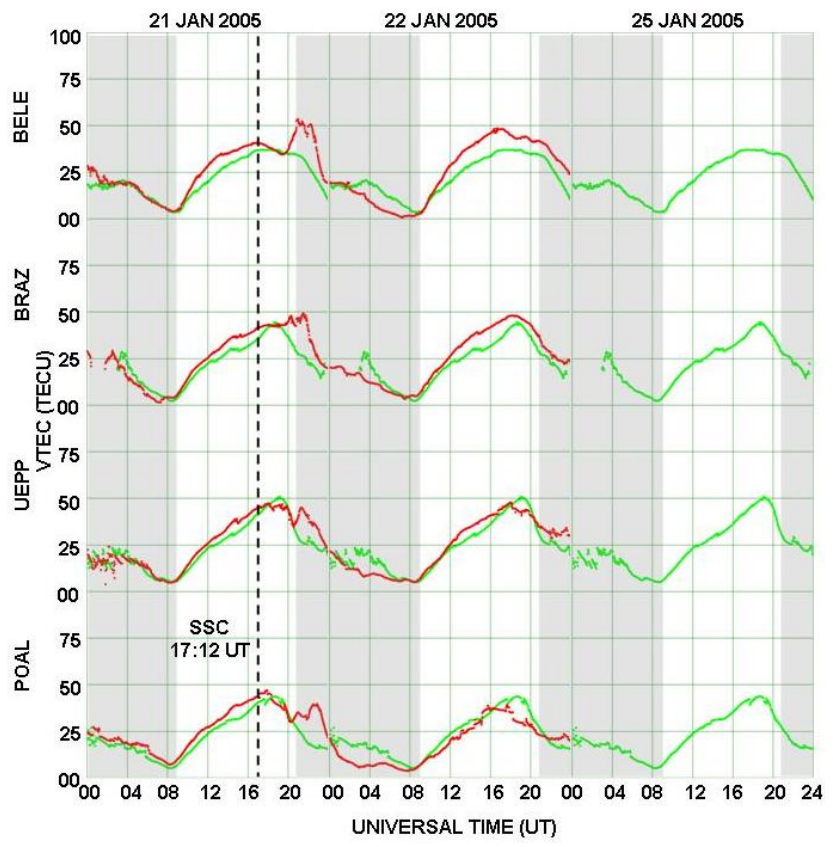

Fig. 7. Average vertical total electron content (VTEC) (TECU) observed at Belem (dip lat. $1.7^{\circ} \mathrm{N}$ ), Brasilia (dip lat. $11.1^{\circ} \mathrm{S}$ ), President Prudente (dip lat. $14.6^{\circ} \mathrm{S}$ ) and Porto Alegre (dip lat. 20.5 ${ }^{\circ} \mathrm{S}$ ) on 21 (red lines), 22 (red lines), and 25 (green lines) January 2005. The dark portions indicate nighttime for these four stations (21:0009:00 UT).

should occur at higher low and middle latitudes, but its effect on VTEC is relatively weak.

In short, the observed phenomenon is clearly related to the prompt penetration electric field and enhanced equatorial fountain effects. The eastward electric field moves the equatorial F-region to higher altitudes, and the plasma particles flow downward to higher latitudes along the geomagnetic field lines and result in the density decrease over the equator.

The simulations of TIME-GCM perhaps do not include the appropriate prompt penetration electric fields in this case, which would give rise to the differences. The similarity between the TIME-GCM simulation and observations is much closer at near mid-latitude station RAM. Figures 5 and 6 indicate that the observed $N m \mathrm{~F} 2$ and $h m \mathrm{~F} 2$ values at RAM are fairly close to the simulated values from the TIME-GCM results. The model appears to underestimate the $h m \mathrm{~F} 2$ and $N m \mathrm{~F} 2$ for much of the time at SJC, although the pre-reversal enhancement at 20:00-22:00 UT during the storm period appears to be reasonably well modeled.

Figure 7 shows the average vertical total electron content (VTEC) observed at BELE, BRAZ, UEPP and POAL on UT days 21 and 22 January (red lines). The observations of average quiet time VTEC from 25 January (green lines) have also been repeated on 21 and 22 January for comparison. Figure 7 shows large increases in the average VTEC at all the GPS receiving stations soon after the SSC (20:00 UT) and positive ionospheric storm phase (10:00 UT on 22 January) at BELE and BRAZ during the recovery phase. At all the four sites, the average VTEC was enhanced during 20:00-24:00 UT on 21 January consistent with the NmF2 increases noted in Fig. 5. Since the AE maximum occurred at 17:45 UT, then disturbance dynamo effects had enough time (3-4 h) to reach the sector under consideration by the local post-sunset time and could reduce the normal upward drift, thus causing the height reductions in Fig. 6.

After 00:00 UT on 22 January, the VTEC was well below the quiet level consistent with the low $N m \mathrm{~F} 2$ shown in Fig. 5. The decrease of nighttime VTEC is a typical signature of negative ionospheric storms. During the later main phase or recovery phase of a geomagnetic storm, composition changes of the atmosphere can propagate to low latitudes, and an enhanced $\mathrm{N}_{2}$ component causes the decrease of the plasma density (e.g. Crowley et al., 1989; Meier et al., 2005; Crowley and Meier, 2008).

Figure 8 shows the variations of the F-peak virtual height for six different frequencies ( 3 to $8 \mathrm{MHz}$ ) observed at Manaus and S. J. Campos on 21, 22, 25, and 26 January 2005. On the storm day of 21 January, the F-layer over the equatorial station, MAN, moved upward during 17:12-20:00 UT, but the movement became downward during 20:00-24:00 UT. In contrast, the F-layer over the low latitude station, SJC, started to move upward at $\sim 20: 00 \mathrm{UT}$, and the upward movement lasted $\sim 2.5 \mathrm{~h}$. These features can also be clearly seen in Fig. 8 .

Figure 7 shows that the average VTEC was enhanced over four GPS stations located between dip latitude $1.7^{\circ} \mathrm{N}$ and $20.5^{\circ} \mathrm{S}$ during 20:00-24:00 UT on 21 January. Although there was no measurement of VTEC over MAN, it can be seen in Fig. 5 that the F-region peak electron density, $N m \mathrm{~F} 2$, also showed a large increase during this period. An unusual phenomenon is that VTEC over middle and low latitudes was enhanced although the F-layer moved downward at the equatorial latitudes but upward at low and middle latitudes.

In order to explain the observations, it is necessary to consider what caused the vertical movement of the ionospheric F-layer. As presented in Fig. 5, the dayside ionospheric electric field was eastward during 17:23-20:00 UT on 21 January and became westward during 20:00-24:00 UT. The eastward electric field was the penetration electric field driven by the large solar wind pressure (Huang et al., 2008) and caused enhanced equatorial fountain effect.

Penetration electric fields cause an enhanced fountain effect over the magnetic equator and results in a decrease of plasma density and VTEC. The daytime westward electric field after 20:00 UT is most likely to be driven by the disturbance dynamo process and causes a reverse fountain (Balan et al., 1995, 1997), which can also result in changes of VTEC.

The F-region peak height over the equatorial region (JIC and MAN) moved upward during 17:23-20:00 UT, and 

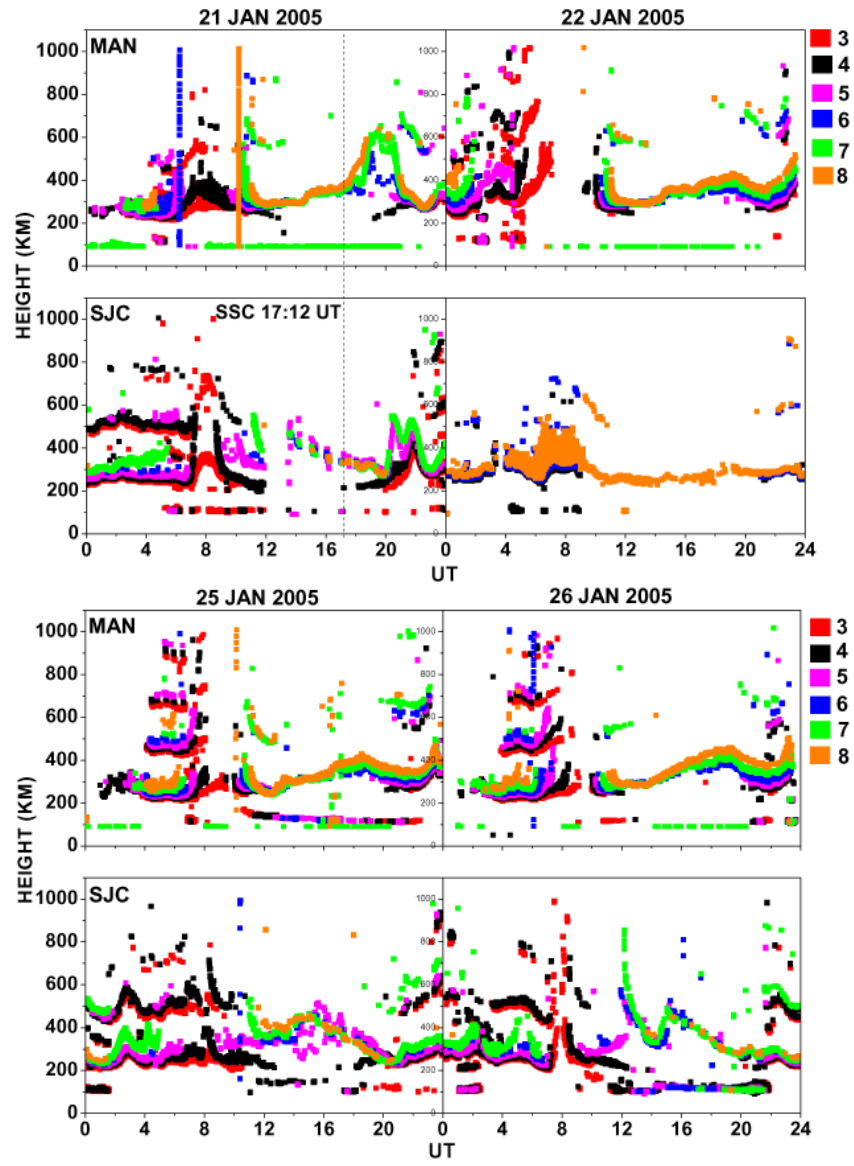

Fig. 8. Plots of virtual height variations for six different frequencies (3 to $8 \mathrm{MHz}$ ) (Iso-frequencies) observed at Manaus (top panel) and S. J. Campos (bottom panel) for UT days 21, 22, 25, and 26 January 2005.

$N m \mathrm{~F} 2$ was decreased. The ionospheric electric field became westward after 20:00 UT. A westward electric field drives the F-layer to move downward and causes an increase of the F-peak density and TEC. The downward movement of the F-layer and the resultant increase of $N m \mathrm{~F} 2 / \mathrm{TEC}$ with westward electric field are the opposite process of the enhanced fountain with eastward electric field, which was termed the reverse fountain by Balan et al. (1995, 1997). Our observations are consistent with the simulations of Balan et al. (1995, 1997).

The westward electric field after 20:00 UT on 21 January was probably produced through the wind disturbance dynamo. Neutral wind disturbances cause the movement of plasma particles along the geomagnetic field lines. The magnetic field lines are nearly horizontal over the equatorial region, so neutral winds cannot directly drive plasma motion in the vertical direction through neutral-ion collisions. The vertical movement of the equatorial F-layer is primarily controlled by the dynamo electric field. At low and middle latitudes, the movement of the F-layer is determined by the combined contribution of neutral winds and dynamo electric field. The wind disturbances are generated in the auroral zone and travel toward the equatorial region. The equatorward winds push the plasma particles to move upward along the magnetic field lines, while the westward dynamo electric field drives the plasma particles to move downward across the field lines. If the wind effect dominates over the dynamo effect, the F-layer at low and middle latitude will move to higher altitudes, resulting in an increase of $N m \mathrm{~F} 2$ and TEC. In our case, the $N m \mathrm{~F} 2$ and VTEC at low and middle latitudes were enhanced during 20:00-24:00 UT on 21 January, implying that the disturbance winds were dominant there.

Figure 9 shows the GPS phase fluctuations (Aarons et al., 1996) (time rate change of TEC in the units of TECU $\mathrm{min}^{-1}$ ) on 21, 22, 25, and 26 January. These phase fluctuations indicate the presence or absence of a few $\mathrm{km}$ scale-size equatorial ionospheric irregularities or equatorial spread-F (ESF) (Aarons et al., 1997). It is observed from Fig. 9, that no phase fluctuations are present on the storm night of 21-22 January. All the other nights (20-21, 22-23, 24-25, 25-26, and 26-27 January) show the presence of phase fluctuations up to UEPP in the pre-midnight (local-time) sector starting at about 21:00 LT. As mentioned earlier this could be due to disturbance dynamo effect. Sahai et al. (2000) using the OI $630 \mathrm{~nm}$ all-sky imaging observations of equatorial plasma bubble observations have previously noted the frequent occurrence of ESF during the month of January in both high and low solar activity. Abdu (1997) has pointed out that while the prompt penetration enhances the upward drift and the disturbance dynamo tends to reduce the upward drifts inhibiting the formation of ESF.

As mentioned earlier the magnetic storm on 21 January was unusual because the main phase of the storm occurred during northward IMF and the maximum $d \mathrm{Dst} / d t$ was between 20:00 and 22:00 UT under northward IMF. The ionospheric electric field during northward IMF should be controlled by the normal electrodynamic process. There are clear indications of pre-reversal enhancements during quiet times on 22, 25, and 26 January (Figs. 6 and 8). A check of the Jicamarca magnetometer data indicated the electrojet was negative during this period and implies that the dayside equatorial ionospheric electric field was westward between 20:00 and 22:00 UT. The ionospheric electric field should be the disturbance dynamo electric field. This dynamo field would cause a downward drift of the F-region plasma. Therefore, the disturbance dynamo electric field inhibited the formation of ESF in the Latin American sector on this geomagnetically disturbed night.

Figure 10 shows global GPS-TEC maps for three UT times on 21 and 22 January (left hand column). The three storm times are 14:00 UT on 21 January (before the storm); 22:00 UT on 21 January (during the storm); 16:00 UT on 22 January (recovery phase). The corresponding quiet-time GPS maps obtained on 25 January are also shown in the right hand column for comparison. A comparative study of 

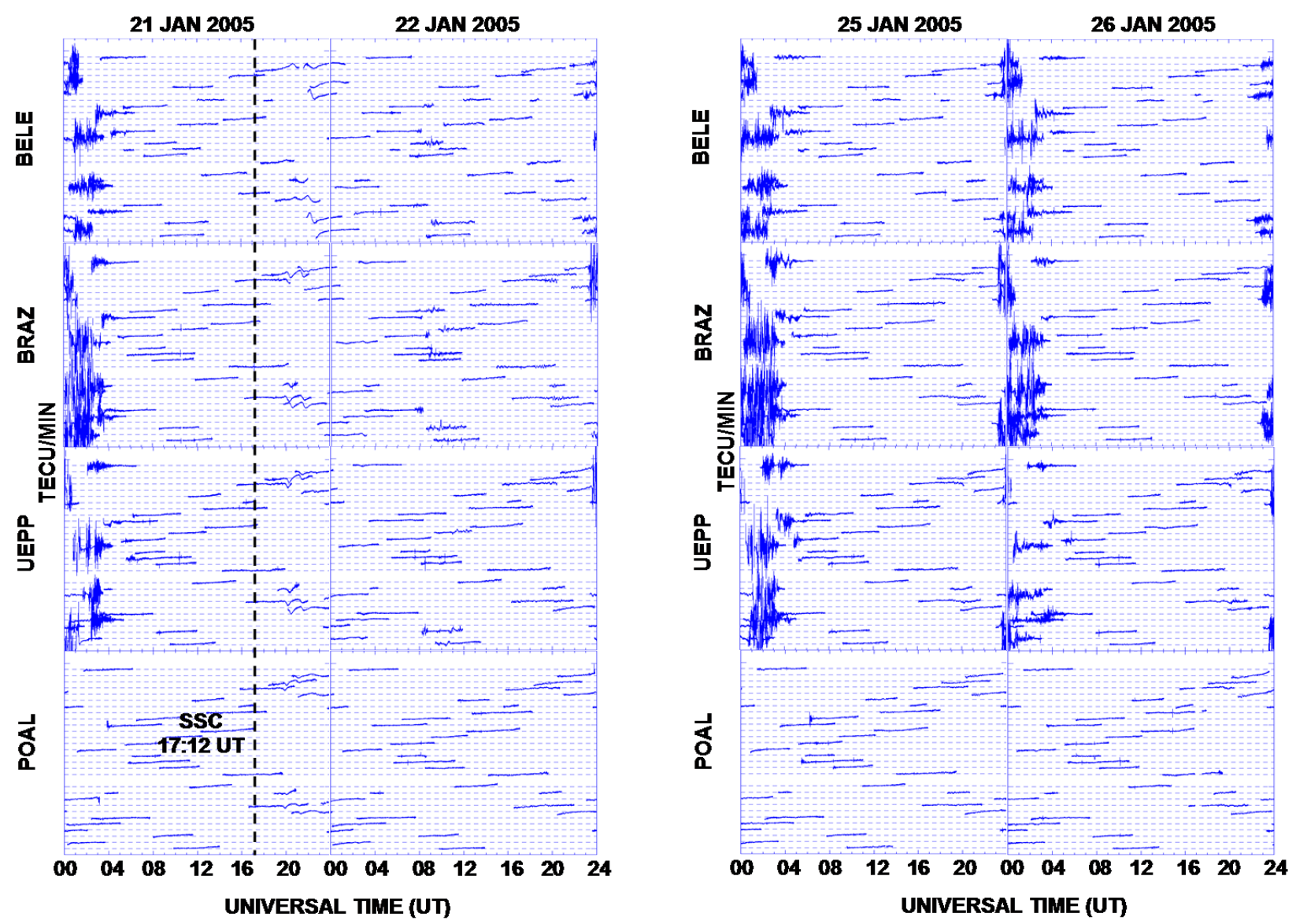

Fig. 9. Phase fluctuations (time rate change of TEC (TECU min ${ }^{-1}$ ) observed at Belem, Brasilia, President Prudente, and Porto Alegre on 21, 22, and 25 January 2005.

storm and quiet periods clearly shows the strong effect of the storm on global TEC. Figure 10 (middle panel) shows much stronger formation of the equatorial ionospheric anomaly (EIA) in the Pacific Ocean region during the storm conditions.

\section{Conclusions}

In this paper, we present the analysis of the response of the ionospheric F-region in the Latin American sector during the intense geomagnetic storm on 21-22 January 2005, using ionospheric sounding observations from four stations covering the equatorial to mid-latitude stations. We also present the GPS observations from four receiving stations in the Brazilian sector during the storm and quiet periods. The principal results are as follows:

1. An unusual uplifting of the F-layer peak soon after the SSC at JIC and MAN (Fig. 6), possibly due to prompt penetration electric field in the dayside ionosphere. A decrease in $N m \mathrm{~F} 2$ at JIC and MAN during this period of uplifting has been observed (Fig. 5). However, the midlatitude station RAM shows a small increase in $N m \mathrm{~F} 2$ at this time.

2. The VTEC (BELE, BRAZ, UEPP, and POAL; Brazilian sector; Fig. 7) and NmF2 (RAM, JIC, MAN, and SJC; Latin American sector; Fig. 5) were enhanced during 20:00-24:00 UT on 21 January.

3. Both the $N m$ F2 and VTEC (except $N m$ F2 at RAM; Fig. 5) were well below quiet levels in the Brazilian sector after 00:00 UT on 22 January (Figs. 5 and 7).

4. Normally during the month of January, we have postsunset ESF on all the nights in the Brazilian sector. This is clearly seen in Fig. 9 (see also Fig. 6; spread-F) as phase fluctuations on the nights of 20-21, 24-25, 2526, and 26-27 January. However, on the night of 21-22 January (geomagnetic storm), we have a suppression effect due to the disturbance electric field which inhibited the development of ESF. 


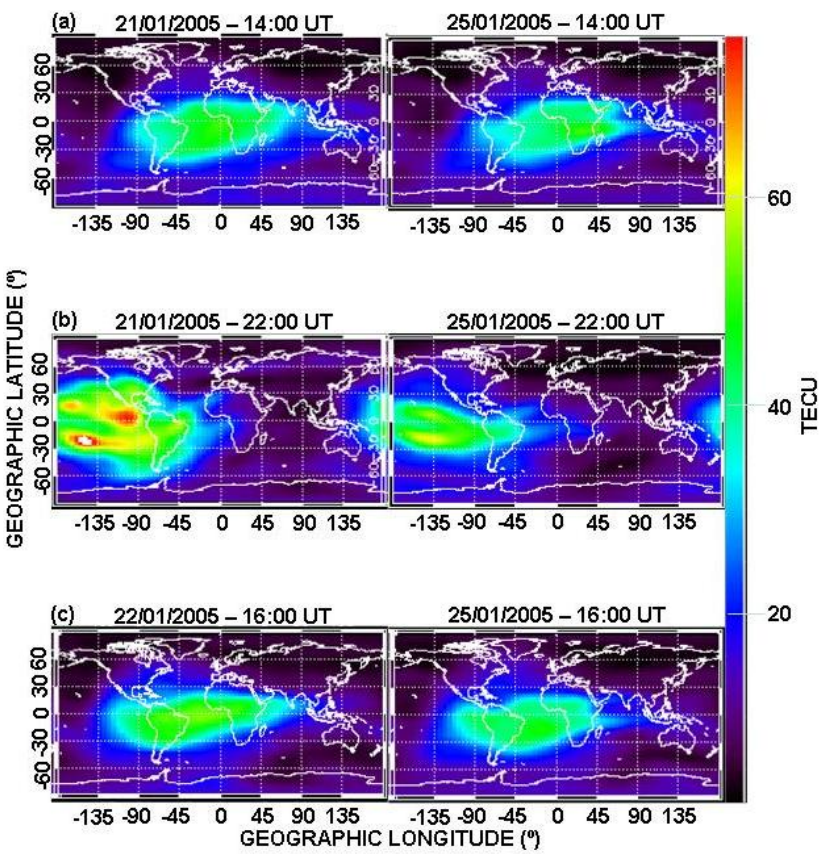

Fig. 10. Three GPS-TEC maps for 21 and 22 January (14:00 UT - before the storm; 22:00 UT - during the storm; 16:00 UT - recovery phase) (left hand column) and three GPS-TEC maps for 25 January geomagnetically quiet (right hand column) conditions for comparison.

5. Drastic TEC variations due to the storm can be seen in Fig. 10. The middle panel of Fig. 10 shows intensification during the storm in the EIA region (stronger effect is seen in the Pacific region, which is in daytime). Possibly the prompt penetrating electric field in the daytime ionosphere caused extreme $\boldsymbol{E} \times \boldsymbol{B}$ uplift in the equatorial region resulting in stronger EIA in this sector.

6. The changes in ionospheric parameters especially at low and equatorial latitudes should be due to prompt penetration electric fields than disturbance dynamo but it also depends on local time, phase of the storm and IMF$B_{\mathrm{Z}}$ orientation. The identification of mechanism is complex.

7. The TIME-GCM simulation results have been included in Figs. 5 and 6. Both similarities and differences from the observed results are noted. The relative effects of prompt penetration and disturbance dynamo E-fields requires further study.

Acknowledgements. Thanks are due to the scientific funding agencies CNPq and FAPESP, Brazil, for the financial support. The Jicamarca and Ramey ionospheric sounding data were downloaded from the Digital Ionogram Data base (DIDBASE) from the site http://ulcar.uml.edu/DIDB/DIDBHome.html. We thank the authorities of the "Rede Brasileira de Monitoramento Contínuo de GPS (RBMC)", Brazil, for kindly allowing us to use the data obtained by the RBMC. The GPS-TEC maps presented were obtained from the site http://cdaweb.gsfc.nasa.gov/sp_phys/. G. C. was supported by NSF Grant ATM-0852393 and Subcontract \# 1387677 from NASAJPL.

Topical Editor K. Kauristie thanks two anonymous referees for their help in evaluating this paper.

\section{References}

Aarons, J., Mendillo, M., and Yantosca, R.: GPS phase fluctuations in the equatorial region during the MISETA 1994 campaign, J. Geophys. Res., 101, 26851-26862, 1996.

Aarons, J., Mendillo, M., and Yantosca, R.: GPS phase fluctuations in the equatorial region during sunspot minimum, Radio Sci., 32, 1535-1550, 1997.

Abdu, M. A.: Major phenomena of the equatorial ionospherethermosphere system under disturbed conditions, J. Atmos. Sol.Terr. Phy., 59, 1505-1519, 1997.

Anderson, D., Anghel, A., Yumoto, K., Ishitsuka, M., and Kudeki, E.: Estimating daytime vertical ExB drift velocities in the equatorial F-region using ground-based magnetometer observations, Geophys. Res. Lett., 29(12), 1596, doi:10.1029/2001GL014562, 2002.

Balan, N., Bailey, G. J., Moffett, R. J., Su, Y. Z., and Titheridge, J. E.: Modeling studies of the conjugate-hemisphere differences in ionospheric ionization at equatorial anomaly latitudes, J. Atmos. Terr. Phys., 57, 279-292, 1995.

Balan, N., Bailey, G. J., Abdu, M. A., Oyama, K. I., Richards, P. G., MacDougall, J., and Batista, I. S.: Equatorial plasma fountain and its effects over three locations: Evidence for an additional layer, the $F_{3}$ layer, J. Geophys. Res., 102(A2), 2047-2056, 1997.

Batista, I. S., de Paula, E. R., Abdu, M. A., and Trivedi, N. B.: Ionospheric effects of the March 13, 1989 magnetic storm at low and equatorial latitudes, J. Geophys. Res., 96, 13943-13952, 1991.

Blanc, M. and Richmond, A. D.: The ionospheric disturbance dynamo, J. Geophys. Res., 85, 1669-1686, 1980.

Buonsanto, M. J.: Ionospheric storms - A review, Space Sci. Rev., 88, 563-601, 1999.

Crowley, G. and Meier, R. R.: Disturbed O/N 2 Ratios and Their Transport to Middle and Low Latitudes, AGU Midlatitude Ionospheric Dynamics and Disturbances, AGU Geoph. Monog. Series, 181, 221-234, 2008.

Crowley, G., Emery, B. A., Roble, R. G., Carlson Jr., H. C., and Knipp, D. J.: Thermospheric dynamics during September 18-19, 1984 1. Model simulations, J. Geophys. Res., 94, 16925-16944, 1989.

Crowley, G., Freitas, C., Ridley, A., Winningham, D., Roble, R. G., and Richmond, A. D.: Next Generation Space Weather Specification and Forecasting Model, Proceedings of the Ionospheric Effects Symposium, Alexandria, VA, 34-41, October 1999.

Crowley, G., Knipp, D. J., Drake, K. A., Lei, J., Sutton, E., and Lühr, H.: Thermospheric density enhancements in the dayside cusp region during strong BY conditions, Geophys. Res. Lett., 37, L07110, doi:10.1029/2009GL042143, 2010.

Du, A. M., Tsurutani, B. T., and Sun, W.: Anomalous geomagnetic storm of 21-22 January 2005: A storm during northward IMFs, J. Geophys. Res., 113, A10214, doi:10.1029/2008JA013284, 2008. 
Fesen, C. G., Dickinson, R. E., and Roble, R. G.: Simulation of the Thermospheric Tides at Equinox with the National Center for Atmospheric Research Thermospheric General Circulation Model, J. Geophys. Res., 91(A4), 4471-4489, 1986.

Grant, I. F., MacDougall, J. W., Ruohoniemi, J. M., Bristow, W. A., Sofko, G. J., Koehler, J. A., Danskin, D., and Andre, D.: Comparison of plasma flow velocities determined by the ionosonde Doppler drift technique, SuperDARN radars, and patch motion, Radio Sci., 30, 1537-1549, 1995.

Hagan, M. E., Burrage, M. D., Forbes, J. M., Hackney, J., Randel, W. J., and Zhang, X.: GSWM-98: Results for migrating solar tides, J. Geophys. Res., 104, 6813-6827, 1999.

Heelis, R. A., Lowell, J. K., and Spiro, R. W.: A model of the high latitude ionospheric convection pattern, J. Geophys. Res., 87, 6339-6345, 1982.

Huang, C.-S., Yumoto, K., Abe, S., and Sofko, G.: Low-latitude ionospheric electric and magnetic field disturbances in response to solar wind pressure enhancements, J. Geophys. Res., 113, A08314, doi:10.1029/2007JA012940, 2008.

Kane, R. P.: Cosmic ray ground level enhancements (GLEs) of October 28, 2003 and January 20, 2005: A simple comparison, Rev. Bras. Geofis., 27(2), 165-179, 2009.

Kikuchi, T., Hahsimoto, K. K., and Nozaki, K.: Penetration of magnetospheric electric fields to the equator during a geomagnetic storm, J. Geophys. Res., 113, A06214, doi:10.1029/2007JA012628, 2008.

Lee, D.-Y., Choi, K.-C., Ohtani, S., Lee, J. H., Kim, K. C., Park, K. S., and Kim, K.-H.: Can intense substorms occur under northward IMF conditions?, J. Geophys. Res., 115, A01211, doi:10.1029/2009JA014480, 2010.

Matthiä, D., Heber, B., Reitz, G., Meier, M., Sihver, L., Berger, T., and Herbst, K.: Temporal and spatial evolution of the solar energetic particle event on 20 January 2005 and resulting radiation doses in aviation, J. Geophys. Res., 114, A08104, doi:10.1029/2009JA014125, 2009.

Mckenna-Lawlor, S., Li, L., Dandouras, I., Brandt, P. C., Zheng, Y., Barabash, S., Bucik, R., Kudela, K., Balaz, J., and Strharsky, I.: Moderate geomagnetic storm (21-22 January 2005) triggered by an outstanding coronal mass ejection viewed via energetic neutral atoms, J. Geophys. Res., 115, A08213, doi:10.1029/2009JA014663, 2010.

Meier, R. R., Crowley, G., Strickland, D. J., Christensen, A. B., Paxton, L. J., Morrison, D., and Hackert, C. L.: First look at the 20 November 2003 superstorm with TIMED/GUVI: Comparisons with a thermospheric global circulation model, J. Geophys. Res., 110, A09S41, doi:10.1029/2004JA010990, 2005.
Orus, R., Cander, L. R., and Hernandez-Pajares, M.: Testing regional vertical electron content maps over Europe during 17-21 January 2005 sudden weather event, Radio Sci., 42, RS3004, doi:10.1029/2006RS003515, 2007.

Richmond, A. D. and Kamide, Y.: Mapping electrodynamic features of the high-latitude ionosphere from localized, observations: Technique, J. Geophys. Res., 93, 5741-5759, 1988.

Richmond, A. D., Ridley, E. C., and Roble, R. G.: A thermosphere/ionosphere general circulation model with coupled electrodynamics, Geophys. Res. Lett., 19, 601-604, 10.1029/92GL00401, 1992.

Roble, R. G.: Energetics of the Meosphere and Thermosphere, AGU Geoph. Monog. Series, 87, 1-21, 1995.

Roble, R. G. and Ridley, E. C.: An auroral model for the NCAR thermospheric general circulation model (TGCM), Ann. Geophys. Ser. A, 5, 369-382, 1987.

Roble, R. G. and Ridley, E. C.: Thermosphere-IonosphereMesosphere-Electro Dynamics General Circulation Model (TIME-GCM): Equinox solar cycle minimum simulations (300500 km), Geophys. Res. Lett., 22, 417-420, 1994.

Sahai, Y., Fagundes, P. R., and Bittencourt, J. A.: Transequatorial Fregion ionospheric plasma bubbles: solar cycle effects, J. Atmos. Sol.-Terr. Phy., 62, 1377-1383, 2000.

Schunk, R. W. and Sojka, J. J.: Ionosphere-thermosphere space weather issues, J. Atmos. Terr. Phys., 58, 1527-1574, 1996.

Senior, C. and Blanc, M.: On the control of magnetospheric convection by the spatial distribution of ionospheric conductivities, J. Geophys. Res., 89, 261-284, 1984.

Spiro, R. W., Wolf, R. A., and Fejer, B. G.: Penetration of highlatitude-electric-field effects to low latidudes during SUNDIAL 1984, Ann. Geophys., 6, 39-50, 1988.

Sreeja, V., Devasia, C. V., Ravindran, S., Pant, T. K., and Sridharan, R.: Response of the equatorial and low-latitude ionosphere in the Indian sector to the geomagnetic storms of January 2005, J. Geophys. Res., 114, A06314, doi:10.1029/2009JA014179, 2009.

Veenadhari, B., Alex, S., Kikuchi, T., Shinbori, A., Singh, R., and Chandrasekhar, E.: Penetration of magnetospheric electric fields to the equator and their effects on the low-latitude ionosphere during intense geomagnetic storms, J. Geophys. Res., 115, A03305, doi:10.1029/2009JA014562, 2010. 